\title{
A 45-Year-Old Male with HIV, Kaposi's Sarcoma, and Squamous Cell Carcinoma of the Skin
}

\author{
Jascha Rubin, MD \\ Thomas Jefferson University, jascharubin@hotmail.com \\ Hasan Bayat, MD \\ Thomas Jefferson University
}

Follow this and additional works at: https://jdc.jefferson.edu/tmf

Part of the Medicine and Health Sciences Commons

Let us know how access to this document benefits you

\section{Recommended Citation}

Rubin, MD, Jascha and Bayat, MD, Hasan (2012) "A 45-Year-Old Male with HIV, Kaposi's Sarcoma, and Squamous Cell Carcinoma of the Skin," The Medicine Forum: Vol. 13 , Article 19.

DOI: https://doi.org/10.29046/TMF.013.1.020

Available at: https://jdc.jefferson.edu/tmf/vol13/iss1/19

This Article is brought to you for free and open access by the Jefferson Digital Commons. The Jefferson Digital Commons is a service of Thomas Jefferson University's Center for Teaching and Learning (CTL). The Commons is a showcase for Jefferson books and journals, peer-reviewed scholarly publications, unique historical collections from the University archives, and teaching tools. The Jefferson Digital Commons allows researchers and interested readers anywhere in the world to learn about and keep up to date with Jefferson scholarship. This article has been accepted for inclusion in The Medicine Forum by an authorized administrator of the Jefferson Digital Commons. For more information, please contact: JeffersonDigitalCommons@jefferson.edu. 


\section{A 45-Year-Old Male with HIV, Kaposi's Sarcoma, AND Squamous Cell Carcinoma of The Skin}

Jascha Rubin, MD and Hasan Bayat, MD

\section{Case}

A 45-year-old male with a history of human immunodeficiency virus, (HIV), on highly active antiretroviral therapy (HAART), Kaposi's sarcoma, and squamous cell carcinoma (SCC) of the right lower extremity complicated by chronic wound formation presented with worsening right leg pain and increasing wound drainage.

The patient described the pain as excruciating, with $10 / 10$ intensity and exacerbated by movement. His wounds began draining purulent material and blood about two weeks prior to presentation. He has had several similar, though milder episodes in the past requiring hospitalization. When the wounds began to have a foul odor, he presented to the hospital. On review of systems, the patient reported new-onset back pain that began approximately one week prior to admission. The pain was constant, sharp, worse with movement, and had an insidious onset. He also had a recent $30 \mathrm{lb}$ weight loss with worsening fatigue. He denied fevers and chills.

His medical history included HIV and Kaposi's sarcoma in the right groin, both diagnosed concomitantly five years ago. Soon after diagnosis he had been started on HAART, and underwent chemotherapy with paclitaxel and liposomal doxorubicin. He subsequently developed multiple wounds spreading over his right leg. These became complicated by recurrent infections with methicillin resistant Staphylococcus aureus (MRSA) requiring surgical debridement and intravenous antibiotics. Two months prior to admission his wounds were biopsied and pathology revealed a poorly differentiated SCC. He continued to undergo wound management as an outpatient while plans were made to reevaluate his new malignancy. His medications on admission included Atripla, hydromorphone, fluconazole, TMP-SMX, omeprazole, ondansetron, and ibuprofen.

The patient lived at home with his same sex partner. He worked in the restaurant business before becoming disabled. He had recently quit smoking but has a 20 pack year history, a remote history of cocaine abuse, and was a social alcohol consumer. His family history was notable for diabetes and hypertension.

On physical exam, the patient's vital signs were all within normal limits. He was a frail man with temporal wasting. He was in no acute distress and was alert and oriented. His mucous membranes were dry without evidence of thrush. He had no cervical or supraclavicular lymphadenopathy. His cardiovascular, pulmonary, and abdominal exams were unremarkable. There was diffuse tenderness to palpation over the thoracic and lumbar spine. On his right lower extremity there were confluent, raised, macerated tumors, extending from the knee to ankle, with involvement of his plantar foot, 2nd, and 3rd digits (Figure 1). A foul smelling, sero-sanguinous drainage was observed emanating from these growths.

On admission, laboratory studies were notable for a white blood cell count of $11.1 \times 109 / \mathrm{L}$, hemoglobin of $7.8 \mathrm{mg} / \mathrm{dL}$, platelets of $409 \times 109 / \mathrm{L}$. Serum chemistry was notable for sodium of $127 \mathrm{mmol} / \mathrm{L}$. His CD4 count was 208 cells/uL and HIV viral load was $14,400 \mathrm{IU} / \mathrm{mL}$. A computed tomography (CT) scan of the chest, abdomen and pelvis revealed mural thickening throughout the entire esophagus and proximal stomach, retroperitoneal lymphadenopathy, and a pathologic compression fracture at the level of L2. An magnetic resonance imaging (MRI) of the right lower extremity demonstrated innumerable subcutaneous fluid collections in the right leg, with abscess formation in the antero-medial aspect of the proximal leg eroding into the tibial cortex. There was diffuse nodular skin thickening with enhancement around his tumors (Figure 2). Wound cultures from his leg grew MRSA and Pseudomonas aeruginosa.

\section{Hospital Course}

The patient required numerous packed red blood cells transfusions, intravenous antibiotics, and aggressive wound care. He underwent CT-guided biopsy of the pathologic lumbar spine fractures. The pathology from these specimens was consistent with metastatic SCC. The patient was seen in consultation by surgery, medical oncology, radiation oncology, gastroenterology and infectious disease. He was offered amputation of his leg, but adamantly declined this option. He opted instead for a course of palliative chemotherapy.

\section{Discussion}

Infection with HIV has long been known to increase the risk of developing cancer. Classically these cancers are included in the category of AIDS-defining illnesses, and are found in patients with poor viral suppression. Among the well known examples are Kaposi's sarcoma, primary central nervous system lymphoma, non-Hodgkin's lymphoma, and invasive cervical cancer. Mainstays of therapy for these malignancies have always included HAART. The improved use and delivery of HAART has prolonged the lifespan of HIV-infected patients. In the post-HAART era there has been an increasing incidence of non-AIDS-defining malignancies (NADM). These NADMs have emerged as an important cause of morbidity and mortality in the HIV-infected population. ${ }^{1-3}$

Since the mid-1990s the estimated number of AIDS-defining cancers has decreased by greater than threefold, whereas the number of NADMs has increased by approximately threefold. ${ }^{5}$ This increased incidence is partly a result of improved screening 
and diagnostic modalities for cancer, as well as patient longevity and increased prevalence of HIV infection. However, NADMs, after correcting for risk factors, have occurred in higher incidences than in the general population, despite appropriate viral suppression. ${ }^{1,4-6}$ One study by the American Cancer Society showed that in the HIV population the rates of developing NADMs within the United States was more than double that of the general population, with a rate of 980 new NADMs per 100,000 person-years. $^{7}$

The traditional risk factors for cancer, such as genetics and carcinogen exposure, apply to patients with HIV-infection. Incidence does not increase with low CD4 nadirs. ${ }^{7}$ NADMs typically have a far more aggressive course than similar malignancies in the general population. The exact mechanisms responsible for the increased incidence and worse clinical course of these malignancies in the HIV population remains unclear. ${ }^{3,7}$ CD4 lymphopenia, cell mediated immune dysfunction, change in cytokine profile and role of HIV proteins, have all been postulated to play a role in tumor development. ${ }^{10}$ Immunosuppression without CD4 depletion may also play a role. This has been demonstrated by studies comparing organ transplant recipients to the HIV population, both of whom share a similar profile of cancer types and rates of occurence. ${ }^{8}$

A number of specific NADMs have been identified as having increased incidence with HIV infection. These include anal cancer, Hodgkin's disease, head and neck cancers, testicular cancer, prostate cancer, basal cell cancer, SCC of the skin, and melanoma. ${ }^{3,7}$ Among these cancers, the cutaneous NADMs are the most frequent, occurring at a rate of $6 \%$ in patients with HIV, supplanting Kaposi's sarcoma as the most common malignancy in this population. ${ }^{9}$

SCC has been demonstrated in multiple case studies to be highly aggressive in the setting of HIV. It presents at a significantly younger age than non-HIV patients (44 versus 70 years), has been associated with a high risk for local recurrence, metastasis, and has a $50 \%$ mortality risk. ${ }^{9-13}$ The major risk factors for developing skin cancer with concomitant HIV infection are mostly the same as in the general population, including fair-skin, family history, and sun exposure. ${ }^{14}$ More than half of patients diagnosed with SCC have a history of genital warts, suggesting a possible link with human papillomavirus (HPV) infection. However no direct link has yet been established between HPV infection and SCC in HIV patients. ${ }^{10,15}$

The management of NADMs in patients with HIV can be challenging for a variety of reasons. Patients with HIV often have significant co-morbidities that can affect performance status and treatment options. Staging the cancer can also be unreliable in the setting of reactive lymphadenopathy typically found with HIV infection. Other concerns include the combined toxicity of chemotherapy and HAART, as well as the immunosupressive effects of chemotherapy in already high-risk patients. Despite these obstacles, management should involve an aggressive, multidimensional approach. Therapy should include HAART, regardless of CD4 counts. ${ }^{16}$ Choices for chemotherapy should be tailored to the patient and the tumor. Wide excisions with careful analysis of margins should be performed to avoid recurrence. ${ }^{10}$ There should also be special attention to prophylaxis against opportunistic infections while administering treatment.

\section{Conclusion}

Infection with HIV has long been associated with an increased risk of developing cancer. In the post-HAART era, there has been an increasing incidence of malignancies not classically included in the category of AIDS-defining illnesses. This is partly due to improved patient survival and cancer screening, but is also linked to HIV infection itself. Most of these cancers present at an earlier average age than in the general population, and are highly aggressive. Heightened screening vigilance is thus called for in the HIV population. Inclusion of HAART remains a cornerstone of management, as does a highly aggressive and multidisciplinary approach to managing the malignancy.

The morbidity and mortality due to aggressive SCC is dependent on the initial control of the local or metastatic disease. Physicians treating SCC should ensure that their patients receive adequate resection with margin control. They should consider local or regional adjunctive radiation and/or chemotherapy as well as sentinel node procedures for high risk tumors. The initial CD4 count does not alter the approach to these cancers. Primary prevention is essential to improved survival, so regular screening exams and early biopsies of suspicious lesions are strongly advocated. ${ }^{10}$

\section{Acknowledgement}

The authors would like to thank Dr. William Short for his guidance and encouragement. His expertise in this subject is greatly appreciated.

\section{References}

1. Pantanowitz L, Dezube BJ. Evolving spectrum and incidence of non-AIDSdefining malignancies. Curr Opin HIV AIDS 2009; 4:27.

2. Silverberg MJ, Abrams DI. AIDS-defining and non-AIDS-defining malignancies: cancer occurrence in the antiretroviral therapy era. Curr Opin Oncol 2007; 19:446.

3. Cooley TP. Non-AIDS-defining cancer in HIV-infected people. Hematol Oncol Clin North Am 2003; 17:889.

4. Long JL, Engels EA, Moore RD, Gebo KA. Incidence and outcomes of malignancy in the HAART era in an urban cohort of HIV-infected individuals. AIDS 2008; 22:489.

5. Shiels MS, Pfeiffer RM, Gail MH, et al. Cancer burden in the HIV-infected population in the United States. J Natl Cancer Inst 2011; 103:753.

6. Kiely B, O’Flaherty J, Surah S, et al. HIV-related malignancies pre- and post-highly active antiretroviral therapy: experiences in an inner city tertiary referral centre. Int J STD AIDS 2010; 21:332.

7. Burgi A, Brodine S, Wegner S, et al. Incidence and risk factors for the occurrence of non-AIDS-defining cancers among human immunodeficiency virus-infected individuals. Cancer 2005; 104:1505.

8. Grulich AE, van Leeuwen MT, Falster MO, Vajdic CM. Incidence of cancers in 
people with HIV/AIDS compared with immunosuppressed transplant recipients: a meta-analysis. Lancet 2007; 370:59.

9. Crum-Cianflone N, Hullsiek KH, Satter E, et al. Cutaneous malignancies among HIV-infected persons. Arch Intern Med 2009; 169:1130.

10. Wilkins K, Turner R, Dolev JC, et al. Cutaneous malignancy and human immunodeficiency virus disease. J Am Acad Dermatol 2006; 54:189.

11. Nguyen P, Vin-Christian K, Ming ME, Berger T. Aggressive squamous cell carcinomas in persons infected with the human immunodeficiency virus. Arch Dermatol 2002; 138:758-63.

12. DeBoer WA, Danner SA. HIV infection and squamous cell carcinoma of sun-exposed skin [letter]. AIDS 1990;4(1):91.
13. Overly WL, Jakubek DJ. Multiple squamous cell carcinomas and human immunodeficiency virus infection [letter]. Ann Intern Med 1987;106(2):334.

14. Lobo DV, Chu P, Grekin RC, Berger TG. Nonmelanoma skin cancers and infection with the human immunodeficiency virus. Arch Dermatol 1992; 128:623.

15. Maurer TA, Christian KV, Kerschmann RL, et al. Cutaneous squamous cell carcinoma in human immunodeficiency virus-infected patients. A study of epidemiologic risk factors, human papillomavirus, and p53 expression. Arch Dermatol 1997; 133:577.

16. Stadler RF, Gregorcyk SG, Euhus DM, et al. Outcome of HIV-infected patients with invasive squamous-cell carcinoma of the anal canal in the era of highly active antiretroviral therapy. Dis Colon Rectum 2004; 47:1305.

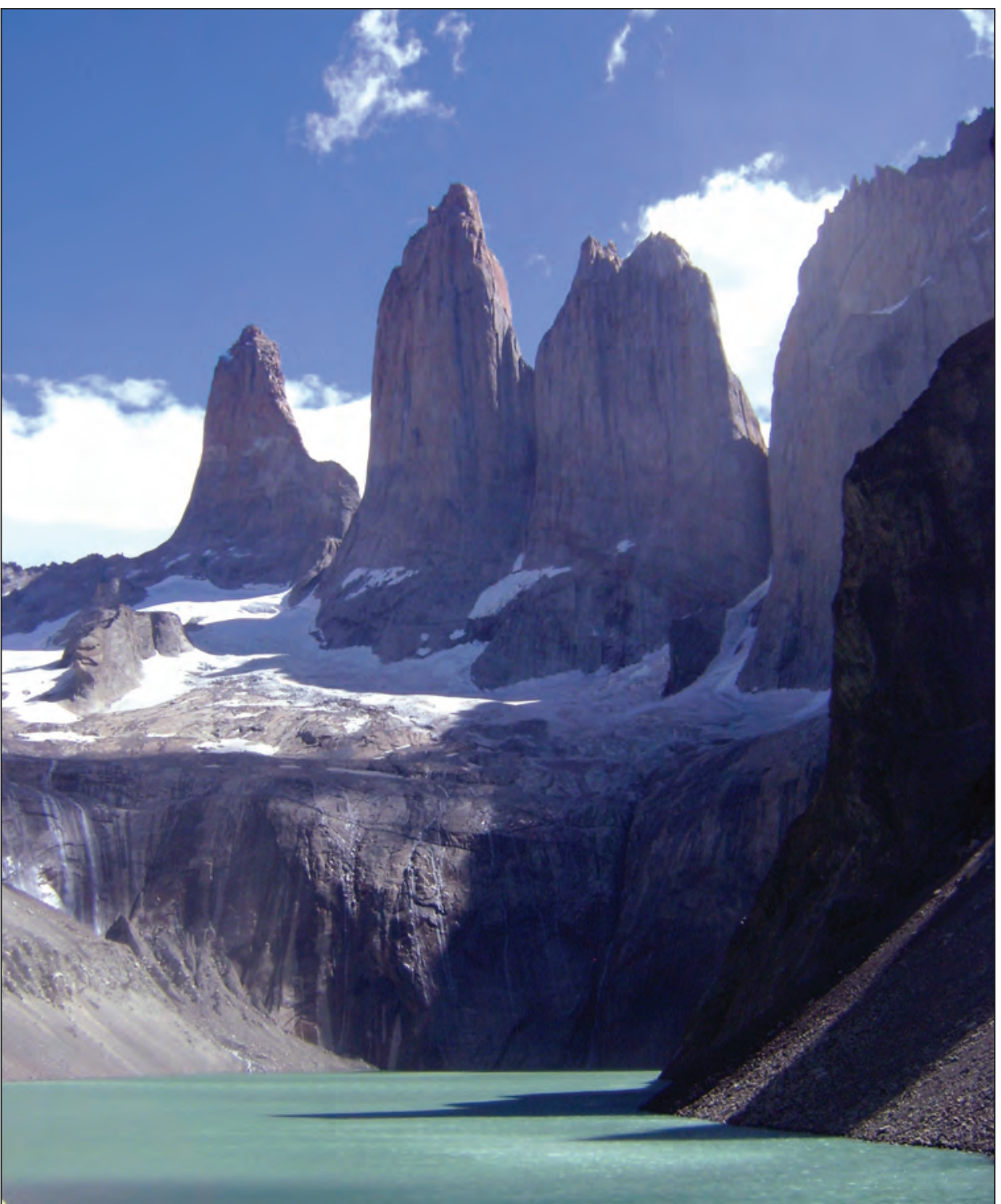

\section{Demons and Dreams}

Mariam Kabir, MD

Demons aplenty

In my life of scanty dreams

Demons aplenty

Taking away my beams.

Once in a while

They scatter away

And I see the light of day.

Once in a while

They leave me alone

And I see what may.

Demons aplenty

In my head of limited space

Crowding out thoughts of joy

Whispering acrimonies

Fears and bitter hitters

Leading me to

Yearn their banishment

From my head

Of limited space,

So I can see

Beams. 
The Medicine Forum, Vol. 13 [2012], Art. 19

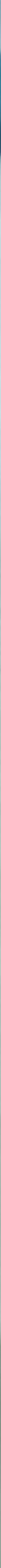




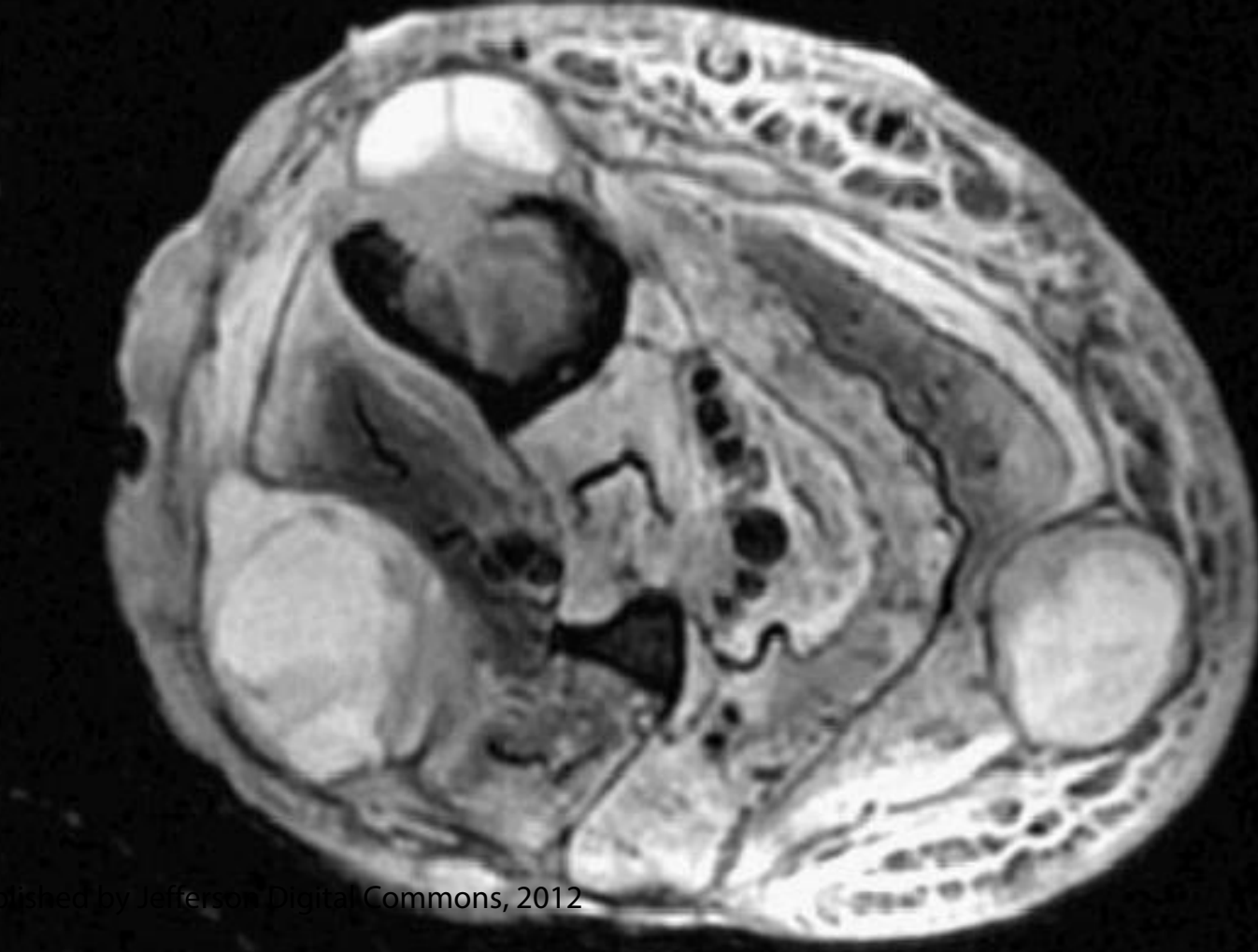

